\title{
A Comparative and Regional Study of Potassium Induced Relaxation of Vascular Smooth Muscle*
}

\author{
R. Clinton Webb ${ }^{* *}$ and David F. Bohr \\ Department of Physiology, University of Michigan Medical School, Ann Arbor, Michigan 48109, USA
}

Accepted November 27, 1979

Summary. The current study was undertaken to assess species and regional variations in the relaxation of vascular smooth muscle in response to potassium and in the ouabain sensitivity of this relaxation. The effect of species variation was investigated through the use of tail arteries from rats, dogs, cats, monkeys, and pigs; the effect of regional variation was studied in tail, middle cerebral, femoral, and posterior coronary arteries from baboons. Helical strips from all of these vessels were made to contract with norepinephrine or serotonin in a potassium-free solution. The vessels relaxed when potassium was added back to the solution. Strips of tail artery from rats, dogs, and monkeys showed greater relaxation in response to potassium than did strips from pigs and cats. Helical strips from tail, cerebral, and coronary arteries of the baboon relaxed to a greater degree in response to potassium than did strips from the femoral artery. Ouabain produced a concentration-dependent decrease in the magnitude of potassium relaxation in all vessel types. Half-maximal inhibition occurred at approximately $10^{-8}$ to $10^{-7} \mathrm{M}$ in all arterial strips except those obtained from rat tail artery $\left(5 \times 10^{-5} \mathrm{M}\right)$. The inhibition of potassium relaxation by ouabain was fully reversed by 30 min exposure to a ouabain-free solution in only the rat tail artery strips. A component of potassium-induced relaxation in tail artery strips from monkeys and baboons was not inhibited by ouabain. The results show that the magnitude of response, potassium and ouabain sensitivity, and recovery from ouabain treatment of potassium relaxation are species related. The regional bed from which the

\footnotetext{
* These studies were supported by NHLBI grant HL-18575

** Dr. Webb was a Post-doctoral Research Fellow of the Michigan Heart Association during this investigation

Abbreviations: ATPase, adenosine triphosphatase; PSS, physiological salt solution; $C$, contractile magnitude from baseline in milligrams; $R$, relaxation measured as residual force above baseline in milligrams; $S E M$, standard error of the mean
}

vascular smooth muscle is derived also determines the magnitude and potassium sensitivity of the relaxation. These parameters of potassium-dependent relaxation may reflect corresponding differences in the electrogenic pumping of sodium and potassium among various animal species and various regional vascular beds.

\section{Introduction}

An appropriate increase in the extracellular concentration of potassium ion produces relaxation of vascular smooth muscle (Bonaccorsi et al., 1977; Chen et a1., 1972; Hendrickx and Casteels, 1974; Konold et al., 1968; Reiner, 1978; Webb and Bohr, 1978). This action of potassium is believed to be the result of activation of sodium-potassium adenosine triphosphatase (ATPase). This enzyme provides the mechanism by which vascular smooth muscle cells maintain high intracellular potassium and low sodium concentration and hence maintains a membrane potential that depends on the membrane permeability to these two ions. Activation of sodium-potassium ATPase also produces hyperpolarization of the membrane since more sodium is moved out of the cell than potassium is moved into the cell. Membrane hyperpolarization causes relaxation of vascular smooth muscle (for review see Anderson, 1976).

Relaxation in response to potassium has been observed in large arteries, such as the aorta (Biamino and Wessel, 1973), as well as in microcirculatory vessels (Duling, 1972). Toda (1976) has observed that this relaxation is greater in cerebral arteries than in peripheral arteries of the dog. Similarly, Bonaccorsi et al. (1977) have reported that the magnitude of potassium relaxation depends on the regional bed from which the vascular smooth muscle is obtained and 
also the species of the animal. The current study was designed to investigate systematically the relaxation in response to potassium in vascular smooth muscle from different animal species and from different vascular beds.

\section{Materials and Methods}

Tail arteries isolated from rats (male and female, $250-400 \mathrm{~g}$ ), dogs (male and female, $14-20 \mathrm{~kg}$ ), pigs (male, $30-50 \mathrm{~kg}$ ), cats (male and female, $3-4.5 \mathrm{~kg}$ ), and monkeys (Rhesus male and female, 8-16 kg) were used in experiments aimed to investigate the effect of animal species on potassium relaxation. Femoral, tail, middle cerebral, and posterior coronary arteries isolated from baboons (male and female, $12-23 \mathrm{~kg}$ ) were used to investigate the effects of blood vessel source on potassium relaxation. The vessels were stored in physiological salt solution (PSS) and cut helically into strips $(0.7-1.5 \times 6.0-10.0 \mathrm{~mm})$ under a dissecting microscope. The helical strips were mounted between a fixed glass base and force transducers (Grass FT03) and suspended vertically in a muscle bath with PSS. The resting tension was adjusted to $500 \mathrm{mg}$ for all arterial strips except strips cut from baboon femoral artery which were adjusted to $1,000 \mathrm{mg}$. All arteries from baboons, dogs, pigs, cats, and monkeys were routinely stored overnight in $80-100 \mathrm{ml}$ of PSS at $4^{\circ} \mathrm{C}$ for experimentation the following day. Rat tail arteries were used on the same day that they were excised. In most experiments on tail arteries, two helical strips from one species were cut and hung in the same muscle bath with two strips from another species. In all experiments on arteries from baboons and some experiments on tail arteries from the different species, one strip was cut from each vessel and hung with other strips from different vessels.

Before the start of experiments, the strips were allowed to equilibrate in the muscle bath for 2 to $3 \mathrm{~h}$. The bathing medium was maintained at $37{ }^{\circ} \mathrm{C}$ and aerated with a mixture of $95 \% \mathrm{O}_{2}$ and $5 \% \mathrm{CO}_{2}$. The $\mathrm{pH}$ of the solution was 7.4 and the composition (mmoles/liter) was as follows: $\mathrm{NaCl}(130), \mathrm{KCl}(4.7), \mathrm{NaH}_{2} \mathrm{PO}_{4}$ (1.18), $\mathrm{MgSO}_{4}-7 \mathrm{H}_{2} \mathrm{O}$ (1.17), $\mathrm{CaCl}_{2}-2 \mathrm{H}_{2} \mathrm{O}$ (1.6), $\mathrm{NaHCO}_{3}$ (14.9), dextrose (5.5), and $\mathrm{CaNa}_{2}$ EDTA (0.03). Potassium concentrations in the bath were varied without compensating for changes in tonicity.

Mean values and standard error of the mean (SEM) were calculated. An unpaired or a paired analysis (Student's " $t$ " test) was used to compare the results. The significance level for all analyses was $P<0.05$.

Drugs used were: norepinephrine (Levophed bitartrate, Winthrop Laboratories), serotonin (Sigma Chemical Co.), and ouabain (Nutritional Biochemicals Corp.).

\section{Results}

\section{Effect of Potassium Concentration}

Species Dependency. The tracings in Fig. 1 illustrate the procedure used to evaluate potassium relaxation in tail arteries from different species. Helical strips of tail artery isolated from rats, cats, dogs, pigs, and monkeys were placed in a potassium-free solution for $15 \mathrm{~min}$ before addition of $10^{-7} \mathrm{~g} / \mathrm{ml}$ norepinephrine. Two min later, after the contraction had reached a plateau, the bath concentration of potassium was
TAIL ARTERIES

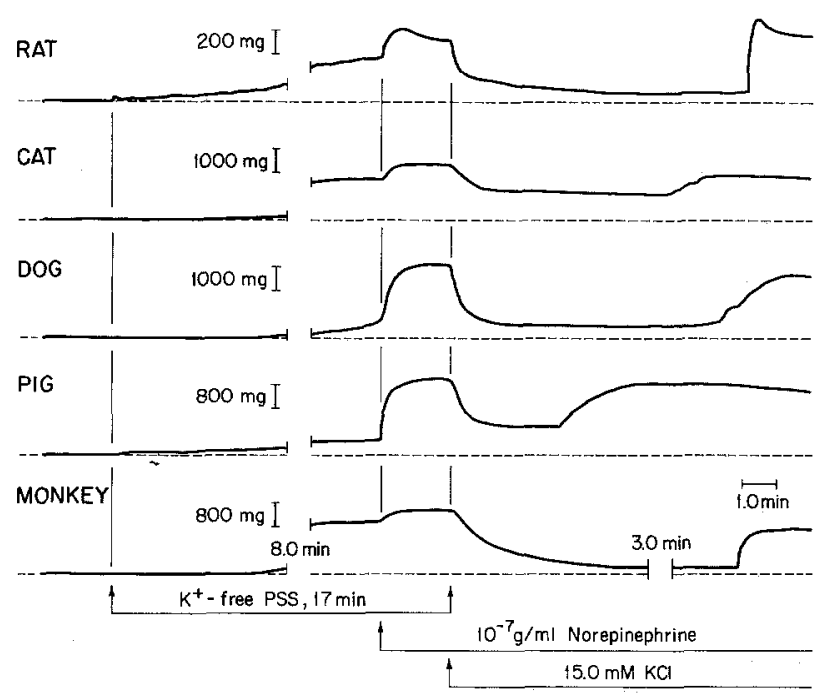

Fig. 1. Potassium induced relaxation of tail arteries from different species. Helical strips of tail artery from rat, cat, dog, pig, and monkey were placed in potassium-free PSS for $17 \mathrm{~min}$. Following $15 \mathrm{~min}$ exposure to potassium-free environment, $10^{-7} \mathrm{~g} / \mathrm{ml}$ norepinephrine was added to the bath. Two min later, $15 \mathrm{mM}$ potassium was added, and a decrease in tension was observed. After a short, but variable period of relaxation, redevelopment of tension occurred spontaneously in all strips

increased to $15.0 \mathrm{mM}$ and an abrupt relaxation occurred. This decrease in tension was quantified as a per cent of the total contraction resulting from incubation in potassium-free solution and the addition of norepinephrine. The calculation of per cent relaxation was performed as follows:

$\%$ Relaxation $=\frac{C-R}{C} \times 100$

where $C=$ contractile magnitude from baseline in $\mathrm{mg}$, and $R=$ relaxation measured as residual force above baseline in $\mathrm{mg}$. Following the relaxation, a redevelopment of tension occurred spontaneously in all strips.

The magnitude of relaxation was found to be related to the concentration of added potassium in all species (Fig. 2). Helical strips of tail artery from rats, dogs, and monkeys showed a significantly greater magnitude of relaxation in response to the addition of potassium (5.0 to $15.0 \mathrm{mM}$ ) than did strips from pigs and cats (Fig. 2). When the magnitude of relaxation at each potassium concentration was normalized to per cent maximum response, it was observed that half-maximal relaxation occurred at lower concentrations of potassium in tail arteries from dogs, while tail arteries from cats required more potassium to produce half-maximal relaxation (Table 1). All other species were intermediate in their dependency on po- 


\section{TAIL ARTERIES}

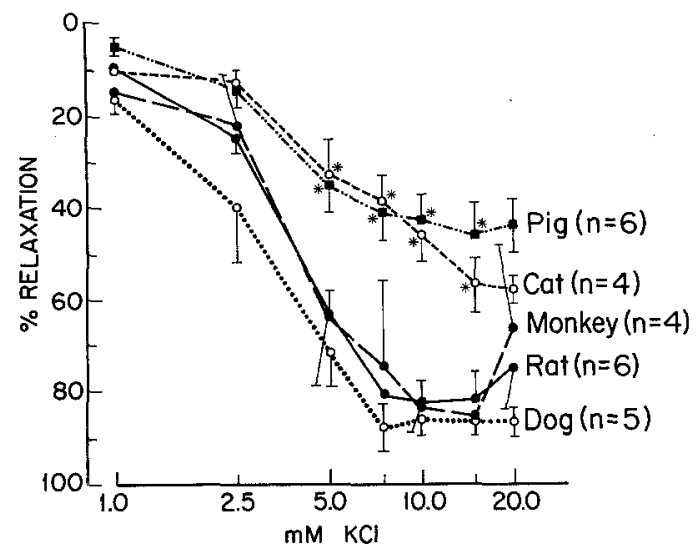

Fig. 2. Concentration-response to potassium: Species variation. Potassium relaxation was performed as described in Fig. 1 except that the concentration of potassium added back to the bath was varied from 1 to $20 \mathrm{mM}$. The magnitude of potassium induced relaxation was related to the concentration of the added potassium in all species. Number of animals used indicated parenthetically. Values are the means \pm standard error of the mean (SEM). Asterisks indicate statistical differences between pig or cat versus monkey, rat, or dog $(P<0.05)$

tassium concentration. Maximal relaxation occurred at 7.5 to $10.0 \mathrm{mM}$ potassium in tail arteries from dogs and rats whereas all other species showed maximal relaxation at 15.0 and $20.0 \mathrm{mM}$ potassium.

Regional Variation. The effect of regional variation on potassium relaxation in vascular smooth muscle was studied in arteries isolated from baboons in a similar manner as described above. The arterial strips
Table 1. Concentration of potassium required to produce half-maximal relaxation: Species and regional variation

\begin{tabular}{llll}
\hline Species & Vessel & $\begin{array}{l}\mathrm{K}^{+} \\
(\mathrm{mM})\end{array}$ & $\begin{array}{l}\text { Number } \\
\text { of animals }\end{array}$ \\
\hline Cat & tail artery & $5.2 \pm 0.9$ & 4 \\
Dog & tail artery & $2.7 \pm 0.4^{*}$ & 5 \\
Monkey & tail artery & $3.8 \pm 0.9$ & 4 \\
Pig & tail artery & $3.5 \pm 0.6^{*}$ & 6 \\
Rat & tail artery & $3.0 \pm 0.3^{*}$ & 6 \\
\hline Baboon & tail artery & $2.5 \pm 0.9^{*}$ & 5 \\
Baboon & femoral artery & $4.7 \pm 0.7$ & 5 \\
Baboon & cerebral artery & $1.3 \pm 0.3^{*}$ & 5 \\
Baboon & coronary artery & $1.6 \pm 0.2^{*}$ & 5 \\
\hline
\end{tabular}

The concentration of potassium required to produce half-maximal relaxation was calculated from the normalized values of Fig. 2 (species variation) and 4 (regional variation) by regression analysis. Asterisks indicate statistical differences between the cat and other species or, in the case of the baboon, statistical differences between the femoral artery and the other arteries $(P<0.05)$

were incubated in potassium-free solution for $20 \mathrm{~min}$ instead of $17 \mathrm{~min}$ before the addition of potassium, and $10^{-7} \mathrm{M}$ serotonin was used to initiate contraction instead of norepinephrine (Fig. 3).

The magnitude of relaxation in response to potassium was observed to be related to the concentration of added potassium in all vessel types (Fig. 4). Helical strips of cerebral, tail, and coronary arteries relaxed to a greater degree in response to potassium (1.0 to

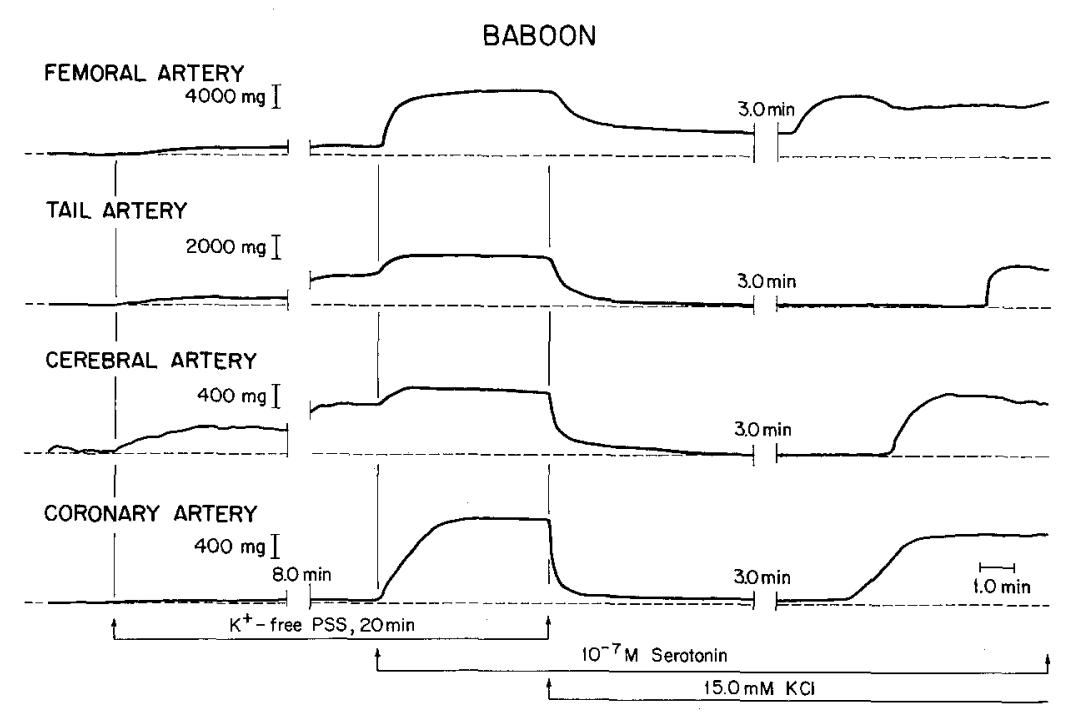

Fig. 3. Potassium induced relaxation of different arteries from the baboon. Helical strips of femoral, tail, cerebral, and coronary arteries from the baboon were placed in potassium-free solution for $20 \mathrm{~min}$. Following $15 \mathrm{~min}$ exposure to potassium-free PSS, $10^{-7} \mathrm{M}$ serotonin was added to the bath. Five min later, $15 \mathrm{mM}$ potassium was added, and a decrease in tension was observed. After a short period of relaxation, redevelopment of tension occurred in all strips 


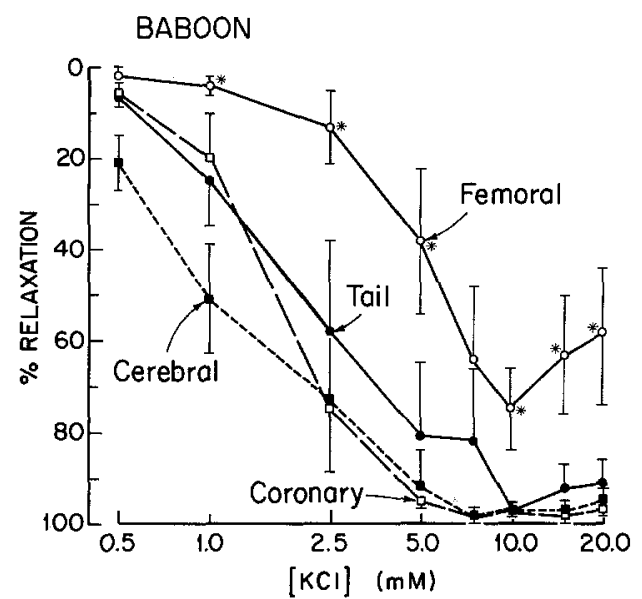

Fig. 4. Concentration-response to potassium: Regional variation. Potassium relaxation was performed as described in Fig. 3 except that the concentration of added potassium was varied from 0.5 to $20 \mathrm{mM}$. The magnitude of potassium induced relaxation was related to the concentration of the added potassium in all vessel types. Values are the means \pm SEM for 5 baboons. Asterisks indicate statistical differences between the femoral artery and the other arteries $(P<0.05)$

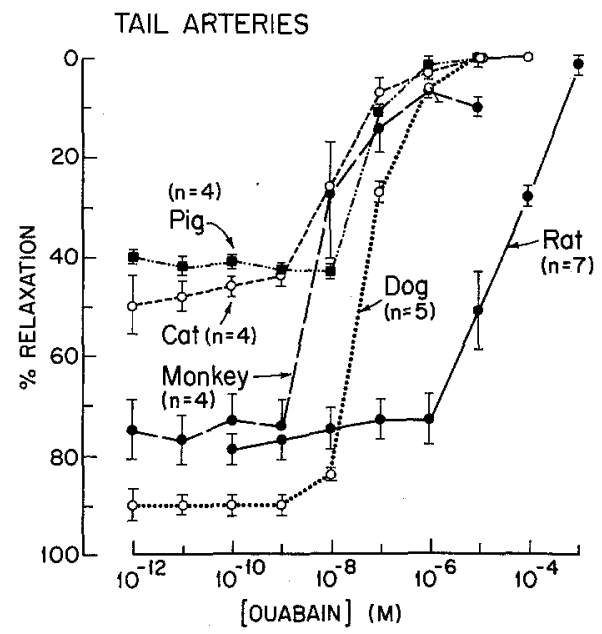

Fig. 5. Concentration-response to ouabain: Species variation. Potassium induced relaxation of tail arteries from different species was performed similar to that described in Fig. 1. Ouabain was added to the bath $5 \mathrm{~min}$ after the beginning of exposure to potassium free solution (12 min prior to the addition of potassium to the bath). Relaxation was induced by addition of $15 \mathrm{mM}$ potassium. Ouabain produced a concentration-dependent suppression of the magnitude of relaxation in all species. Potassium relaxation in the rat was less sensitive to ouabain inhibition than in any other species. Numbers in parentheses represent number of animals. Values are the means $\pm S E M$

$5.0 \mathrm{mM}$ and 10.0 to $20.0 \mathrm{mM}$ ) than did femoral arteries (Fig. 4). Normalization of the relaxation magnitude to per cent maximum response indicated that half-maximal relaxation occurred at lower concentrations of potassium in cerebral and coronary arteries, whereas femoral arteries required a higher concentra-
Table 2. Concentration of ouabain required to produce half-maximal inhibition of potassium relaxation: Species and regional variation

\begin{tabular}{llll}
\hline Species & Vessel & $\begin{array}{l}\text { Ouabain } \\
(\mathrm{M})\end{array}$ & $\begin{array}{l}\text { Number } \\
\text { of animals }\end{array}$ \\
\hline Cat & tail artery & $2.7 \times 10^{-8 *}$ & 4 \\
Dog & tail artery & $5.3 \times 10^{-8 *}$ & 5 \\
Monkey & tail artery & $1.6 \times 10^{-8 *}$ & 4 \\
Pig & tail artery & $4.2 \times 10^{-8 *}$ & 4 \\
Rat & tail artery & $3.6 \times 10^{-5}$ & 7 \\
\hline Baboon & tail artery & $6.4 \times 10^{-8}$ & 5 \\
Baboon & femoral artery & $2.2 \times 10^{-8}$ & 5 \\
Baboon & cerebral artery & $7.8 \times 10^{-8}$ & 5 \\
Baboon & coronary artery & $6.1 \times 10^{-8}$ & 5 \\
\hline
\end{tabular}

The concentration of ouabain required to produce half-maximal inhibition of potassium relaxation was calculated from the normalized values of Fig. 5 (species variation) and 6 (regional variation) by regression analysis. Asterisks indicate statistical differences between the rat and the other species $(P<0.05)$

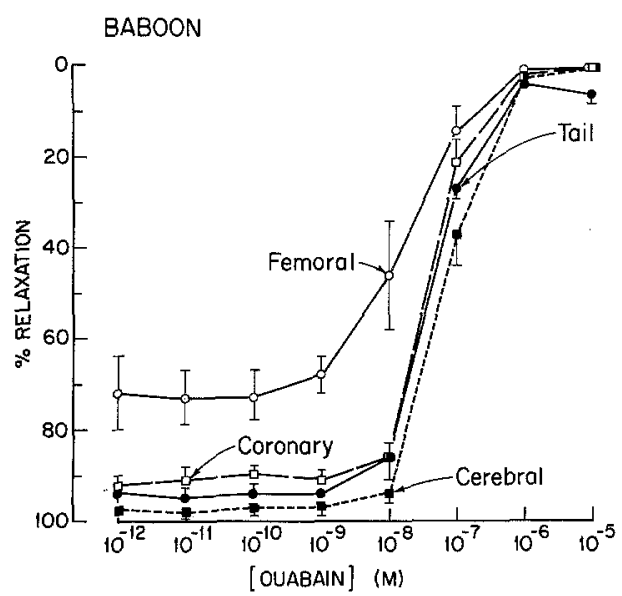

Fig. 6. Concentration-response to ouabain: Regional variation. Potassium induced relaxation of baboon arterial strips was performed as described in Fig. 3. Ouabain $\left(10^{-12}\right.$ to $\left.10^{-5} \mathrm{M}\right)$ was added to the bath $5 \mathrm{~min}$ after the beginning of exposure to potassium-free solution (15 min prior to the addition of potassium to the bath). Relaxation was induced by addition of $15 \mathrm{mM}$ potassium. Ouabain produced a concentration-dependent inhibition of the magnitude of potassium relaxation in all vessel types. All of the vessel types showed similar sensitivities to ouabain. Values are the means $\pm \mathrm{SEM}$ for 5 baboons

tion to produce half-maximal relaxation (Table 1). Tail arteries were intermediate in their responsiveness to the addition of potassium. Maximal relaxation occurred at $7.5 \mathrm{mM}$ potassium in cerebral and coronary arteries, whereas femoral and tail arteries showed maximal relaxation at $15.0 \mathrm{mM}$ potassium. 


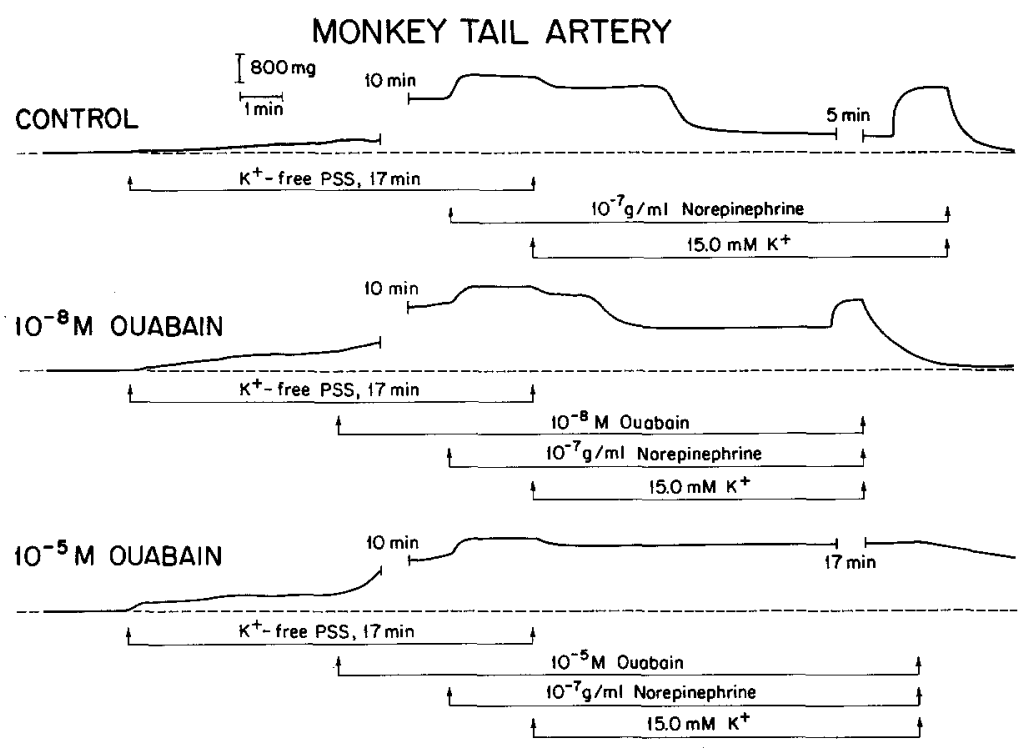

Fig. 7. Effect of ouabain on potassium relaxation of tail arteries from monkeys. Potassium relaxation of monkey tail artery was performed as described in Fig. 1. When potassium was returned to the bath, the strip responded biphasically (upper tracing). There was a small initial relaxation followed by a larger response. The initial relaxation was insensitive to treatment with ouabain $\left(10^{-8}\right.$ and $10^{-5} \mathrm{M}$ shown) whereas the secondary response was eliminated (lower tracing)

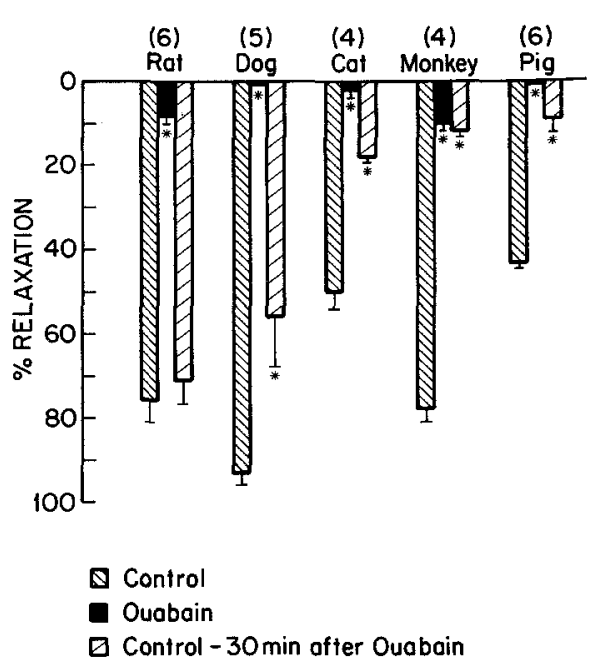

Fig. 8. Recovery from ouabain inhibition. Thirty min following the completion of a concentration-response to ouabain (as in Fig. 5), a control response was performed to test the recovery from ouabain treatment. Recovery from ouabain treatment was complete only in the rat tail arteries. Number in parentheses represent the number of animals. Values are the means \pm SEM. Asterisks indicate statistical differences from control values for each species $(P<0.05)$

\section{Inhibition of Potassium Relaxation by Ouabain}

Species Dependency. Ouabain, an inhibitor of sodiumpotassium ATPase, was found to cause a decrease in the magnitude of potassium induced relaxation in tail arteries from all species (Fig. 5). This inhibition of potassium relaxation was dependent upon the concentration of ouabain. The concentration of ouabain which produced a $50 \%$ change from control values was between $10^{-8}$ and $10^{-7} \mathrm{M}$ in all species except the rat (Table 2).
Regional Variation. Ouabain also produced a decrease in the magnitude of potassium relaxation in all vessel types from the baboon (Fig. 6). This inhibitory action was dependent upon the concentration of ouabain. The concentration of ouabain which produced a $50 \%$ change from control values was between $10^{-8}$ and $10^{-7} \mathrm{M}$ in all strips (Table 2).

Effect of Ouabain on Potassium Relaxation of Monkey and Baboon Tail Arteries. Tail artery strips isolated from monkeys and baboons frequently showed a biphasic response to the addition of potassium (Fig. 7). There was a small initial relaxation of variable duration which was insensitive to ouabain treatment, followed by a larger relaxation, which was inhibited by ouabain. When present, the biphasic relaxation usually occurred at potassium concentrations between 2.5 and $15.0 \mathrm{mM}$ potassium. In tail artery strips from these animals which showed a monophasic response to potassium, ouabain treatment was ineffective in inhibiting the total relaxation (see Figs. 5 and 6). This biphasic response to potassium was not observed in any of the other vessel types.

Recovery from Ouabain Inhibition. Thirty min following the completion of a concentration-response to ouabain (Fig. 5), a control relaxation to potassium was performed to test the rate of recovery from ouabain treatment in tail arteries from different species (Fig. 8). The inhibitory effect of ouabain on potassium relaxation was completely reversible in only the rat at this short interval. Relaxation responses at 30 min after ouabain had been rinsed from the bath 
returned to approximately $50 \%$ of the control level before inhibition in dog tail artery strips. Tail arteries from the pig and cat showed partial recovery $(20-30 \%)$, whereas the tail artery strips from monkeys showed no recovery. Tail arteries from all species showed near control levels of potassium relaxation at 120 min after washout of ouabain.

\section{Discussion}

The goal of the present study has been to evaluate systematically potassium relaxation of anatomically similar blood vessels (tail arteries) from different species and from different regional vascular beds of the same species (baboon). The observations of this investigation may be summarized as follows: 1) the phenomenon of potassium relaxation of vascular smooth muscle was common to all species and types of blood vessels; 2) the amplitude of the response and its sensitivity to added potassium was specific to the species and regional vascular bed from which the vascular smooth muscle was obtained; 3) ouabain inhibited potassium relaxation in all preparations and the sensitivity to ouabain and recovery from its action was species specific; and 4) there is a component of potassium relaxation in baboon and monkey tail arteries which was not inhibited by ouabain. The following paragraphs will discuss these observations.

The Phenomenon of Potassium Relaxation. Numerous studies have shown that isolated vascular smooth muscle relaxes when potassium is added to a potassium-deficient bath solution (Biamino and Wessel, 1973; Bonaccorsi et al., 1977; Hendrickx and Casteels, 1974; Konold et al., 1968; Reiner, 1978; Toda, 1976; Webb and Bohr, 1978). This potassium induced relaxation has been attributed to the electrogenic pumping of sodium and potassium by sodium-potassium ATPase (Bonaccorsi et al., 1977; Hendrickx and Casteels, 1974; Reiner, 1978). Bonaccorsi et al. (1977) observed that isolated rat tail artery strips, made to contract in response to serotonin in potassium-free solution, relaxed when potassium was returned to the bathing medium. They suggested that during the incubation in potassium-free solution, the activity of sodium-potassium ATPase is eliminated, and therefore sodium accumulates intracellularly. When potassium is returned to the bath, the enzyme is activated due to the high intracellular concentration of sodium. This results in hyperpolarization which decreases membrane excitability and causes relaxation. Once the pump reduces the intracellular sodium concentration toward normal, its activity decreases and the membrane potential returns toward normal. The presence of serotonin then caused excitation of the smooth muscle and an increase in mechanical response was observed. These interpretations were supported by membrane potential measurements and by the observation that ouabain, an inhibitor of sodium-potassium ATPase activity (Schwartz et al., 1975), eliminated the potassium induced relaxation. Other investigators have suggested the same mechanism for potassium relaxation based on similar experimental observations (Anderson, 1976; Chen et al., 1972; Hendrickx and Casteels, 1974; Reiner, 1978; Webb and Bohr, 1978).

Based on the observations of this investigation, the phenomenon of potassium relaxation appears to be a common characteristic of vascular smooth muscle in all species and regional vascular beds. In contrast, Brecht and Gebert (1971) suggested that relaxation in response to potassium was specific to both the animal species and the blood vessel type. They observed that certain arteries and veins from cows, goats, rabbits, pigs, rats, and guinea-pigs showed no relaxation upon addition of $10 \mathrm{mM}$ potassium. However, it must be pointed out that they equilibrated their preparations in $2.7 \mathrm{mM}$ potassium before the addition of $10 \mathrm{mM}$ potassium. Equilibration in $2.7 \mathrm{mM}$ potassium may not have inhibited sodiumpotassium ATPase sufficiently to permit an effective increase in the intracellular concentration of sodium.

The amplitude of potassium relaxation: Previous observations (Bonaccorsi et al., 1977; Webb and Bohr, 1978) from this laboratory have shown that the amplitude of potassium induced relaxation in rat tail artery increases as the concentration of potassium increases over a range of 1 to $15 \mathrm{mM}$. The current investigation shows that the amplitude of potassium relaxation is characteristically related to the animal species and regional vascular bed from which the vascular smooth muscle is obtained. Helical strips of tail artery from rats, dogs, and monkeys showed greater relaxation in response to potassium than did strips from pigs and cats. Helical strips of tail, cerebral, and coronary arteries from the baboon relaxed to a greater degree than did strips from the femoral artery. Toda (1976) has observed that potassium relaxation of cerebral arteries is greater than that of peripheral arteries. He attributed this difference to the greater content of sodium in cerebral than in peripheral arteries. Webb and Bohr (1978) have shown that the amplitude of potassium-relaxation of rat tail artery increases with the duration of the exposure of vascular smooth muscle to a potassium-free environment. They suggested that the amplitude of relaxation reflected the magnitude of a cumulative process occurring in the absence of potassium. It is known that intracellular sodium accumulates under these conditions and that the level of activity of sodium-potassium ATPase is dependent on the intracellular sodium concentration (Schwartz et al., 1975). 
Four possible mechanisms may be considered for the species and regional individualities observed in the current study: 1) differences in intracellular sodium concentration, 2) differences in sodium-potassium ATPase activity, 3) differences in the rate of the calcium extrusion or sequestration responsible for the relaxation, and 4) differences in the muscle-to-connective tissue ratio of the various arteries. Our observations do not differentiate between these possibilities.

When the amplitude of potassium relaxation at each concentration of added potassium was normalized to per cent maximum relaxation, it was observed that the sensitivity to potassium was also related to the species and regional vascular bed. Halfmaximal relaxation occurred at $2.7-3.8 \mathrm{mM}$ potassium in strips from rats, dogs, monkeys, and pigs. Half-maximal relaxation of tail artery strips from cats occurred at approximately $5.2 \mathrm{mM}$ potassium. Cerebral and coronary arterial strips from the baboon were found to be more sensitive (half maximal response: 1.3 and $1.6 \mathrm{mM}$, respectively) than tail and femoral arterial strips (2.5 and $4.7 \mathrm{mM}$, respectively). These observations may reflect qualitative and quantitative differences in the activation sites for potassium on sodium-potassium ATPase in the different types of blood vessels. It should also be noted that the concentration of potassium required to produce halfmaximal relaxation under the conditions of our experiments is greater than that reported for the enzyme in isolated membrane systems (Schwartz et al., 1975). This difference can probably be attributed to the competition of sodium (present in our PSS) with potassium at potassium activation sites on the enzyme (Schwartz et al., 1975).

Ouabain Inhibition. In the present experiments, ouabain decreased the amplitude of potassium relaxation in all blood vessel types. This effect was concentration-dependent. Half-maximal inhibition occurred at concentrations between $10^{-8}$ and $10^{-7} \mathrm{M}$ ouabain in all arterial strips except those obtained from rat tail artery $\left(5 \times 10^{-5} \mathrm{M}\right)$. The inhibition of potassium relaxation by ouabain was fully reversed $30 \mathrm{~min}$ after removal of the drug from the muscle bath in only the rat tail artery strips.

These findings illustrate that the mechanism of potassium relaxation is similar in all blood vessel types and species. The relative insensitivity and rapid reversal from ouabain treatment in the rat can probably be explained by the fact that sodium-potassium ATPase in this species is less sensitive to ouabain. Allen and Schwartz (1969) have shown that binding of tritiated ouabain could readily be dissociated from the rat cardiac enzyme preparation with concomitant restoration of enzyme activity. However, the glycoside remains tightly bound to enzyme from the dog heart.
The rapid reversibility we have observed in the ouabain inhibition of potassium relaxation in the rat tail artery may reflect a similar phenomenon.

Ouabain-Insensitive Potassium Relaxation. The current experiments illustrate that a component of potassium relaxation in tail arteries isolated from monkeys and baboons is insensitive to ouabain treatment. This component of potassium relaxation may be due to hyperpolarization caused by an increased membrane permeability to potassium which results from the elevated potassium concentration (Biamino and Wessel, 1973). Alternatively the change in the ratio of potassium concentration inside and outside of the cell may directly affect the contractility of the vascular smooth muscle (Norton and Detar, 1972).

Results of this comparative study serve as evidence that sodium-potassium ATPase is involved in potassium relaxation of all vascular smooth muscle. Quantitative individualities occur in the sensitivity of this system to potassium and ouabain in different species and in different vascular beds.

\section{References}

Allen, J.C., Schwartz, A.: A possible biochemical explanation for the insensitivity of the rat to cardiac glycosides. J. Pharmacol. Exp. Ther. 168, 42-46 (1969)

Anderson, D.K.: Cell potential and the sodium-potassium pump in vascular smooth muscle. Fed. Proc. 35, 1294-1297 (1976)

Biamino, G., Wessel, H.J. : Potassium induced relaxation of vascular smooth muscle: A possible mechanism of exercise hyperemia. Pflügers Arch. 343, 95-106 (1973)

Bonaccorsi, A., Hermsmeyer, K., Aprigliano, O., Smith, C.B., Bohr,.D.F.: Mechanism of potassium relaxation of arterial muscle. Blood Vessels 14, 261-276 (1977)

Brecht, K., Gebert, G.: The effect of potassium on vascular smooth muscle. In: Physiology and pharmacology of vascular neuroeffector systems. Bevan, J.A., Furchgott, R.F., Maxwell, R.A., Somlyo, A.P. (eds.), pp. 313-322. Basel: Karger 1971

Chen, W.T., Brace, R.A., Scott, J.B., Anderson, D.K., Haddy, F.J.: Mechanism of the vasodilator action of potassium. Proc. Soc. Exp. Biol. Med. 140, 820-824 (1972)

Duling, B.R.: Effects of potassium ion on the microcirculation of the hamster. Circ. Res. 37, 325-332 (1972)

Hendrickx, H., Casteels, R. : Electrogenic sodium pump in arterial smooth muscle cells. Pflügers Arch. 346, 299-306 (1974)

Konold, P., Gebert, G., Brecht, K.: Effect of potassium on the tone of isolated arteries. Pflügers Arch. 301, 285-291 (1968)

Norton, J.M., Detar, R.: Potassium and isolated coronary vascular smooth muscle. Am. J. Physiol. 222, 474-479 (1972)

Reiner, O.: The role of the electrogenic sodium pump in the potassium relaxation of the rabbit ear artery. Naunyn-Schmiedebergs Arch. Pharmacol. 303, 213-220 (1978)

Schwartz, A., Lindenmayer, G.E., Allen, J.C.: The sodium-potassium adenosine triphosphatase. Pharmacological, physiological and biochemical aspects. Pharmacol. Rev. 27, 3-134 (1975)

Toda, N.: Potassium-induced relaxation in isolated cerebral arteries contracted with prostaglandin $\mathrm{F}_{2} \alpha$. Pflügers Arch. 364, 235-242 (1976)

Webb, R.C., Bohr, D.F.: Potassium-induced relaxation as an indicator of $\mathrm{Na}^{+}-\mathrm{K}^{+}$ATPase activity in vascular smooth muscle. Blood Vessels 14, 198--207 (1978) 